\title{
Rethinking OER and their Use : Open Education as Bildung
}
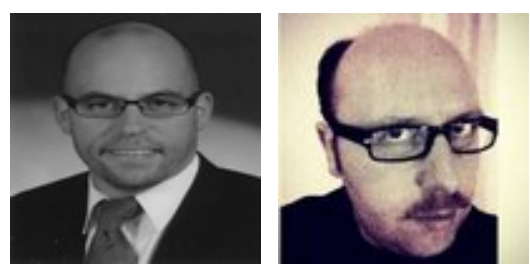

Markus Deimann ${ }^{1}$ and Robert Farrow ${ }^{2}$

${ }^{1}$ FernUniversitaet in Hagen, Germany, ${ }^{2}$ The Open University UK

\section{Abstract}

Despite the recent increases of interest in open education, notably in massive open online courses (MOOCs) (Fini, 2009), it has been continuously asserted that this form of social knowledge production lacks a philosophical or theoretical foundation (Vandenberg, 1975). Similar accusations have been made with respect to distance education, such as being slow to engage with critical debates in theory and research (Evans \& Nation, 1992). In a similar vein, Danaher, Wyer, and Bartlett (1998) claim that researchers in open and distance learning tend to draw on too narrow a range of theoretical resources in their research. Given the considerable rise of open education over recent years, these critical appraisals urge us to expand theoretical approaches and refine our understanding of evolving pedagogical and technological relations (cf. Bell, 2011). In this paper, we contribute to debates surrounding open education and open educational resources by introducing the concept of Bildung (self-cultivation, selfrealization) as a powerful reflective tool and framework for approaching open education. We will elaborate on the potentials of Bildung by reviewing the history of the concept and exploring the extent to which Bildung can provide open education with a theoretical framework. Our focus is not exclusively on open educational resources (OER): We follow other commentators (Mackey \& J acobson, 2011, p. 62; cf. Weller, 2011) who argue that 'openness' in education necessarily shifts the focus from content (OER) to practices (OEP) that are necessary for the use of that content.

We also argue that the beliefs and values associated with Bildung - including autonomy, critical reflection, inclusivity, and embracing the potential for self-development - are suitable for providing a theoretical framework for open education as well as providing a 
critical lens through which to assess contemporary models of education (e.g., Liessmann, 2006).

Keywords : Open educational resources; open education; educational theory

\section{The Impact and Challenges of Open Education}

\section{The Open Education Movement}

The open education movement (OEM) is often thought to have grown out of the open source movement in software development. Open-source software is published with a licence that makes the code available to those who would modify, port, adapt, and share it, and was largely developed in response to the software monopolies that developed through the 1980s. Wiley (1998) coined the phrase open content to describe analogous intellectual properties which are not licensed under conventional copyright restrictions. With the explosion of internet technology over the last twenty years, it has become increasingly easy to share knowledge and information. This had led to new pedagogical possibilities, particularly in the field of distance education. There are now an incredible range of courses, tools, and other materials available on an open basis, including OpenLearn, Connexions, OERGlue, P2PU, MIT OCW, Wikieducator, MITx, OpenStudy, and the Mechanical MOOC. Contemporary open education thus represents a fusion of powerful communication technologies, internet literacy, and pedagogical innovation which is developing into a new creative paradigm for education. This includes a wide range of actors and stakeholders, including a number of advocates who publicly endorse pedagogical and/or institutional 'openness'. These diverse actors are thus united by their broad endorsement of openness in education. Their key commitments might be described as follows:

- A belief that education is undergoing fundamental changes as a result of innovation in digital technologies

- A normative commitment to the idea that knowledge should be free, both to access and develop. In practice this has involved both reducing the cost of education at the point of delivery (such as through open textbooks) as well as courses which are entirely free to participate in, such as the MITx courses

- Encouraging collaboration across disciplinary boundaries and between academics, educators, technologists, and support staff within and beyond educational institutions

- Arguing that we need new pedagogies and systems for intellectual property which are adequate for contemporary education 
- Improving access to education and widening participation by closing the digital divide. (Smith \& Casserly, 2006)

\section{Open Educational Resources}

Open educational resources (OER) are often thought to have developed out of the discourse around learning objects in the 1990s. The term learning-object was first coined in 1994 by Wayne Hodgins, who proposed the development of discrete units of learning which could be delivered electronically. Chiappe (2007) defined the learning object as "a digital self-contained and reusable entity, with a clear educational purpose, with at least three internal and editable components: content, learning activities and elements of context", arguing that "learning objects must have an external structure of information to facilitate their identification, storage and retrieval: the metadata".

OER are teaching, learning, and research resources that reside in the public domain or have been released under an intellectual property license that permits their free use or re-purposing by others. Open educational resources include full courses, course materials, modules, textbooks, streaming videos, tests, software, and any other tools, materials, or techniques used to support access to knowledge. (Atkins et al, 2007, p. 4)

While this definition is often cited, it should be noted that there remains no universally established definition of OER (Geser, 2007). OER include many different kinds of digital and non-digital assets. Learning content might comprise course curricula, learning objects, modules, blogs, and repositories with formats including text, images, audio, video, interactive simulations, and games. By releasing these materials under the appropriate Creative Commons licence, authors can legitimate the use, re-use, reappropriation, and re-mixing of open content. Thus, OER remove restrictions for learners and educators. Creative Commons (2012) offers a range of licences for educational content which are more flexible than the standard "all rights reserved" expression of copyright. In most cases, OER are free of direct cost and generally accessible online, although there are undoubtedly degrees of openness where legal, ethical, business, and pedagogical contexts meet and interact. 


\section{Open Education Practices}

The boundaries of the debate around open education are increasingly expanding in order to focus on the institutional, cultural, and pedagogical implications of adopting the open model rather than supporting focus on the (copyright status of the) resources themselves. The implications of a shift to the mainstream use of OER profoundly challenge existing models of research, scholarship, dissemination, and teaching. OER throw the validity of existing educational systems into question. One central assumption in this regard is the acknowledgement that

traditional ways of providing learning opportunities are no longer adequate to equip teachers, students and workers with the competences required to participate successfully in the emerging knowledge-based society. It is becoming ever more evident that the societal frameworks and conditions are changing at a pace that is not being met by what most educational institutions today offer as learning opportunities. (Geser, 2007, p. 37)

It is often argued that OER can catalyse transformations in education as they offer a more learner-centred approach and problem-solving strategies. Key competences in this regard are closely linked to the utilisation of ICT to search and access information on the Internet. However, there is also a need for new pedagogic practices based on an open paradigm, for instance engaging in open online collaborative projects using wikis or blogs. Currently, we still witness the dominant power of the teacher-centred model in most educational settings. New competences are difficult to enact and are heavily dependent on the engagement of the individual learner. Yet it remains vague how these competencies should be defined as empirical evidence is either lacking or far from conclusive.

\section{Open Education as Bildung}

In this section we introduce the concept of Bildung (self-cultivation, self-realization) as a reflective tool and as a point of orientation and regulation. Our contention will be that there are a number of ways to understand how the modern practice of 'open' education elicits opportunities for learning which may be seen as overlapping or being coterminous with the tradition of Bildung. We proceed by reviewing the genesis and history of the term in the early modern tradition. 


\section{The Concept and History of Bildung}

At the end of the eighteenth century, a conceptual transformation took place in Germany leading to the birth of a new value idea: Bildung. This means that during this time a significant extension occurred so that Bildung from now on signals a new value of its own:

Whereas Bildung was previously a synonym for Erziehung (from erziehen, to 'educate', 'bring up') and was related to Enlightenment [Aufklärung] the idea now encompasses all this and is elevated into the region of culture [Kultur] and 'humanity' [Humanität] more generally. (Dumont, 1994, S. 82)

A classical definition states that Bildung is to be understood as a free, dialogical, and dialectical interplay between the individual and the world which allows and supports the individual's self-realization. Wilhelm von Humboldt (1767 to 1835) coined the expression of a "connection between our ' $\mathrm{I}$ ' with the world in the most general, most lively and freest interaction" (Wellmon, 2010, S. 255). It is thus a "process in the course of which specific human beings acquire the general characteristic human features" (Menck, 2000, S. 93). This process is a never-ending attempt to be able to live a "good life" which was regarded as a fundamental right for every human being.

According to Eldridge (undated) the first references occur in theological debates of the $16^{\text {th }}$ century where devout Christians were encouraged to 'cultivate' (Bildung) themselves in the image of God. Later, philosophers of biology used the word to refer to the inherent potentialities that might explain the development of an organism as it interacts with its environment. Mendelssohn (1997, p. 314) went on to use the term to describe the unfolding of one's potential in a general, cultural sense.

By the $18^{\text {th }}$ century ideas about developing potential were infused with the political and philosophical ideals of the Enlightenment. Eldridge's assertions do seem to be supported by a simple test of concordance. As the following graph shows, there was an explosion in use of the term around 1750. This had subsided by the middle of the next century, with peaks of interest in the term continuing to manifest until a dropping off in the latter half of the $20^{\text {th }}$ century. 


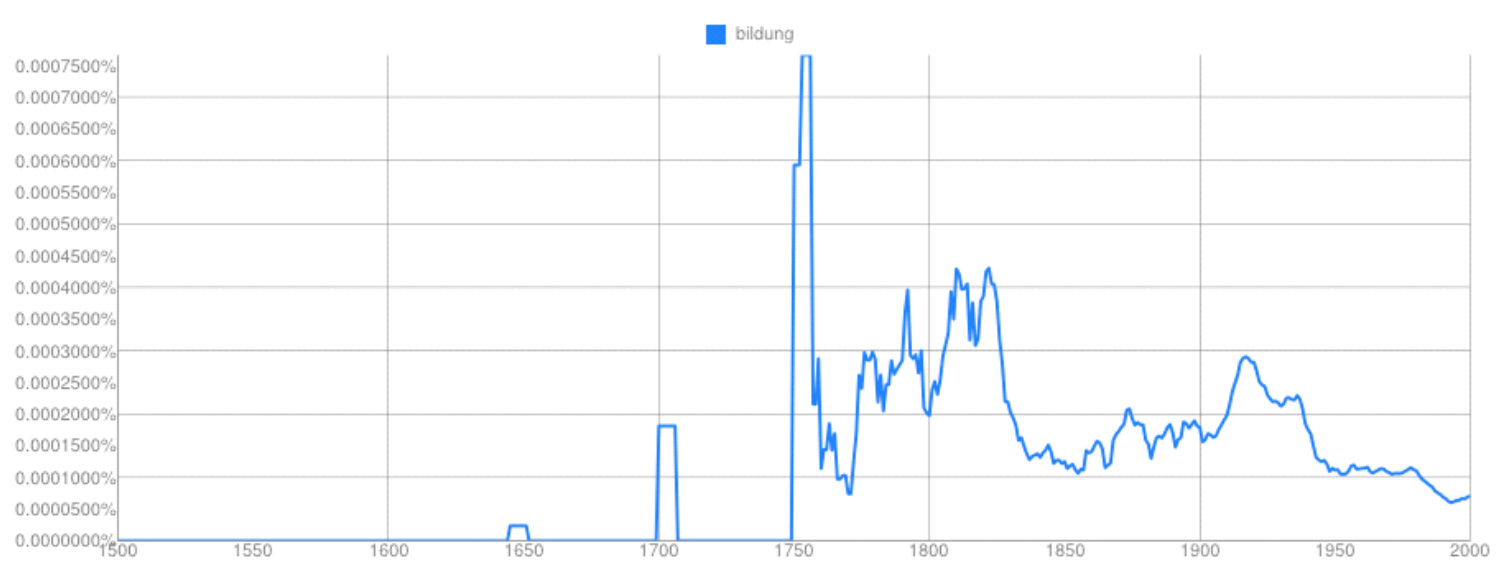

Figure 1. Diagram showing incidence of the term Bildung in German literature, 15002000 (Google, 2012).

In the late $18^{\text {th }}$ century Herder construed Bildung as a kind of natural unfolding which was to be understood culturally and aesthetically. Herder's place as the forerunner of geisteswissenschaftliche Pädagogik (hermeneutically-inspired education studies) is based on his insistence that man's creative and intellectual capacities need to be developed if we are to live virtuous lives. Eldridge suggests that Herder's conception of Bildung is one which replaces academic philosophy with philosophical anthropology. Bildung thus conceived treats criticism and reflection as much a part of human reason as natural science, but without the same manipulative attitude toward the world that one might associate with utilitarian or positivist accounts of human reason (cf. Habermas, 1968).

Following Herder, Humboldt emphasized the unrestrained interplay between the individual and the world, an exchange through which the individual relates to the world in the most comprehensive, vital, and freest way possible. Self-development is not an adaptation to an external order but rather a cultivation of the inner life: a reflective, creative form of self-realization or self-cultivation which, crucially, is achieved in and through relations with others (Sorkin, 1983). Humboldt also advocated informal education that was free from state interference. In the modern Hegelian tradition, Adorno (1973) draws attention to the commercialisation of education, criticizing the factory model of production as a feature of the instrumental reason that characterises modernity [instrumentellen Vernunft]. The poverty of modern educational theories, he contends, is that Bildung has been co-opted by capitalistic production with a drive to increase sales and profits and treating learners as consumers rather than active, reflective agents. Rather than nurturing difference, modern educational paradigms emphasize homogeneity among learners, closed systems, and job training rather than cultivation and education. Authentic Bildung does not conform to market systems and can never be fully subsumed into the status quo (Liessmann, 2006). 
This sense of going beyond existing structures has remained a constant theme in the humanistic tradition. It should be noted that the pedagogical, biological, cultural, and aesthetic elements of Bildung have been controversial ever since Herder's proposal. Since the focus is on the potential for human development, it has functioned as something of a blank canvas for a range of thinkers interested in education (Horlacher 2004, p. 424). Discourse around Bildung is thus always and necessarily mediated, necessarily unresolved, dialectical, and open.

\section{Bildung and Contemporary Education}

In order to clarify the conception of Bildung put forward in this paper, theories of transformative learning which are more familiar to most of the readers may be helpful in explaining some of the core features. As defined by Mezirow (1997, S. 5) "transformative learning [...] is the process of effecting change in a frame of reference". Of critical importance in this definition is the term "frame of reference" which is stated to be "[...] the structures of assumptions through which we understand our experiences" to selectively shape cognitive, conative, and emotional processes. Furthermore, it is assumed that a frame of reference is a relatively stable construct working like a critical lens and sets a "line of action". Modern theories of Bildung (Marotzki, 2003) build on the frame of reference and claim that there are many grand transformations in the society (e.g., digitalisation, globalism) which require a new transformation of the frame of reference. As we have seen, it is now a common practice to "hack" education, that is, to retrieve materials from open repositories all over the world or to collaborate with others in MOOCs. Traditional practices that have been obtained throughout formal educational settings have insofar offered little to help learners with orientation in open complex environments. Bildung may thus be understood as a way of reconsidering learning practices in a way which is appropriate to the challenges of modern education.

Recent theoretical approaches claim that Bildung is more closely linked to media than ever before. More specifically, it is assumed that media are an essential vehicle for Bildung because they represent the world for us (J örissen \& Marotzki, 2008). With the advancement of innovative ICT (social software) Bildung is exposed to new opportunities but also to new challenges. In recent attempts to describe Bildung in changed realities such as virtual worlds or digital spaces, the influence of innovative ICT has gained significant influence (Meister \& Meise, 2010). Of central importance are the extended possibilities for articulation in new social media spaces. Expressing one's opinion in a blog or posting a statement in a discussion forum not only reflects individual Bildung but can also contribute to modifications of individual Bildung. Moreover, Bildung exceeds the dominant perspective of the individual to embrace the social realm. In this way, Bildung enables participation in public affairs and eventually leads to a "participatory culture" (J enkins, 2009) which is assumed to emerge from the so-called Web 2.0 era. 
How can Open Education Benefit from the Introduction of the Theory of Bildung?

It has been consistently suggested that open education lacks a solid theoretical framework. This was the case in earlier writings on the Philosophy of Open Education (Nyberg, 1975) and has continued up to this day (Peters, 2008a). In this regard, it seems astonishing that the massive critics on open education in Germany that have been mostly adopted in schools such as open curriculum were not linked to Bildung despite its influence in theoretical debates. Instead there was a rather vexed discussion which often attempted to demonstrate that openness should be regarded as a buzzword with virtually no exploratory power (Lenzen, 1976). Its foremost function is to subsume critics on the perceived closed systems of education (Nehles, 1981).

On the other hand, openness does point to a critical aspect in theorising Bildung which goes back to the classical writings of Humboldt. He and his contemporaries outlined the notion of Bildung being related to the world to enable the individual to have all the experiences that contribute to becoming a fully developed human being. This was based on a subject-object-dualism that claims that the state of an inward harmony can never be fulfilled without a connection to the external world by engaging and interacting with it and by leaving one's mark. This is a distancing and reflective process. Openness is thus important as an unrestricted access to the world constitutes the precondition for Bildung to take place. This typically takes a form where the person is confronted with a diverse array of (often challenging) experiences which then can be transformed into an integrated self:

The person can... never gather himself enough in the whole human race. The more diversity he transforms into the whole, the richer, and the more powerful and successful he will be. The impact of the multifaceted relations provides him the diversity. The more he opens up (toward the world), the more new sides (and multiple abilities) he can possess, and the more active his inner activities can be so as to develop individually and to combine all together to a whole. (Humboldt, 1797/2002, p. 346, our translation)

Obviously, Humboldt's work is rooted in Idealism and unconcerned by technical issues like access to educational materials and learning on a massive scale. Given the aspiration of theories of Bildung - to capture the contemporary condition - it seems warranted to focus instead on the notion of openness as an enabler of Bildung. Moreover, it can be argued that Bildung and openness are kindred spirits because both share certain moral values around humanity and enlightenment (Deimann, 2013). From this expanded perspective, Bildung can be described as a complex process of interaction between the individual and the world based on a well-grounded understanding of the importance of openness: (1) the person is provided an unrestricted, open access to 
digital artefacts representing the diversity of the world and (2) the world is given traces and manifestations expressing the human spirit that are added to the world's open database. We see today the emergence of many technologies which strive to support these processes. For instance, the OER Evidence Hub developed by the Knowledge Media Institute and the Institute of Educational Technology at The Open University under the auspices of the Open Learning Network aims to provide an environment to systematically interrogate the open education movement on what are the people, projects, organizations, challenges, solutions, and claims to scaffold the movement. In a similar vein, the OER Knowledge Cloud has been established to identify, collect, preserve, and disseminate available documents of enduring value to researchers, industry, government, scholars, writers, historians, journalists, and informal learners.

Open education and Bildung can both be linked to the broader context of web literacies, that is, the abilities to utilize the Web in a way to get the most out of it for personal development. Mozilla Foundation recently issued a paper which defines the four basic web literacies (2013):

1. Exploring - I navigate the Web while learning, questioning and evaluating what it has to offer.

2. Creating - I create things with the Web and solve problems while respecting the work of others.

3. Connecting - I communicate and participate appropriately in one or more Web communities.

4. Protecting - I protect the Web as a public resource for free expression.

This framework resonates with previous attempts outlining the potentialities of digital learning environments for Bildung (Marotzki, Nohl, \& Ortlepp, 2003), which states that first and foremost information has to be transformed into knowledge - an understanding that is reflected in the open education movement by the shift in focus from OER to OEP. Secondly, knowledge should be reflected upon considering a number of factors, including (a) its emergence and constitution, (b) its scope, (c) its justified utilisation, (d) and with reference to the articulation of one's own position (with regard to the reflected knowledge) in public space.

We can see some similarities here with the connectivist approach for understanding MOOCs (Downes, Siemens, \& Cormier, 2013) and other forms of open education, which may be simplified as entailing four steps: aggregation, remixing, repurposing, and feeding forward. However, being focused on the distributed nature of knowledge and cognition this approach neglects to describe the specific procedure that takes place during the process of personal self-transformation. Despite the ways in which transparency and openness to criticism are encouraged in open learning (Smith \& Casserly, 2006) much of the content of these personal transformations remains opaque 
or not well understood. While in a typical MOOC the learner is committed to open up materials from a technological and idealistic standpoint, Bildung elaborates on the importance of openness from a philosophical point of view, providing a way for learners to understand and influence their own intellectual development.

Thus far, building theories around the philosophical and pedagogical particularities of OER has been restricted by relying on concepts from an earlier phase in thinking about educational techniques that may not share the vision and explanatory force of Bildung. During the past two decades learning has become much more multi-faceted and complex, largely due to the proliferation of modern ICT. This has caused an "increasing encroachment on everyday life" and also "boundaries between settings in which people learn and in which they use technology for other activities have blurred" (Kop, 2011, S. 20). Consequently, learning now involves not only cognitive but also social, emotional, and other elements often undertheorised in traditional learning models. Attempts to describe learning and education in these complex contexts can be found, for instance, in the activity theory established through the extensive work of Engeström (2001) who argues that

In important transformations of our personal lives and organizational practices, we must learn new forms of activity which are not yet there. They are literally learned as they are being created. There is no competent teacher. Standard learning theories have little to offer if one wants to understand these processes. (p. 138)

In a similar and parallel vein, open education has emerged as a new paradigm of social production in the global knowledge economy (Peters, 2008b) to challenge existing forms of teaching and learning. In the networked, digital world - and especially in the future - the sheer volume and diversity of content can be overwhelming, what Weller (2011) has referred to as abundance of knowledge in need of pedagogy. Evidently, one of the biggest hurdles for the learner in this kind of online environment is the ability to orientate oneself. There has already been a debate on the increasing information overload that has begun in the so-called knowledge society (Marotzki \&J örissen, 2010). There is a distinct difference between knowledge of how things can be better produced, more efficiently (Verfügungswissen) and knowledge of why or for what reason things are done or produced (Orientierungswissen). Both forms are inversely proportional: Whereas Verfügungswissen is easily accessible due to open formats and open archiving, it does not, however, contribute to an increase of Orientierungswissen. Furthermore, it exacerbates its acquisition. In this context, Bildung is seen as a critical factor for establishing competences that help people to navigate through open, complex worlds by relying on their own creativity and reflection to arrive at deeper understandings of their own educational experiences. 


\section{Bildung as Theoretical Framework: MOOCs, Communities, and Literacy}

Excitement over massively open online courses (MOOCs) continues to mount while satisfaction with traditional forms of college education falls amid ever-rising costs to students and their families and a resulting restriction of access to higher education (particularly in the USA and the UK). High profile education providers from around the world have been working to make open courses available to all. Perhaps the first ground-breaking act was the Massachusetts Institute of Technology launch of the OpenCourseWare (OCW) initiative to make all its courses online and freely accessible. Several other institutions did the same so that rich repositories like MERLOT (Multimedia Educational Resource for Learning and Online Teaching) could be established. More recently, platforms like P2P University or Open Study Group started to offer not only open access to materials but also enabled open practices, including peer support or tutoring.

As they scale, MOOCs "[build] on the active engagement of several hundred to several thousand 'students' who self-organize their participation according to learning goals, prior knowledge and skills, and common interests" (McAuley, Stewart, Siemens, \& Cormier, 2010, p. 4). There are many other providers in this market (including Khan Academy, Coursera, Udacity) and thus MOOCs have already bifurcated into two distinct models: the "classical" (connectivist) MOOCs and the new xMOOCs (Daniel, 2012). However, proponents of MOOCs still emphasise the efficiency, flexibility, and accessibility of massive online instruction and assessment.

MOOCs disrupt a number of long held convictions about organised education. They are open to anybody with an internet connection, a willingness to learn, and a willingness to agree to the honour codes that serve to ward off plagiarism. Traditional higher education directs students towards achieving a degree, and degree programmes often include some materials that are more or less interesting to the student. By selecting their own courses, MOOC learners must direct their own learning at a fundamental level. MOOCs may be radical pedagogical activities in that they often do not specify learning goals or examine the learning process in anything like the typical ways. Assessment of learning is typically peer-based rather than carried out by an instructor. It is thus a totally learner-centred (and learner-driven) approach which is at odds with almost all institutional pedagogy. While the curricula and delivery of learning materials are planned by the course teams, participation in a MOOC is often "emergent, fragmented, diffuse, and diverse. It can be frustrating. It's not unlike life" (McAuley et al., 2010, p.4).

How can learners (and teachers) orient themselves in a MOOC environment when many of their preconceptions about the learning process are based on "closed" institutional models? We propose to frame the question in terms of a new kind of literacy that is informed by theories of Bildung. MOOC learners must take responsibility for their own learning and development to a degree that is arguably greater than that of typical higher 
education students. They must therefore be relatively more autonomous in some ways than typical college students.

Often serving many hundreds of thousands of students, MOOCs are often assumed to improve access to education. Though there are undoubtedly large numbers of students enrolled on such courses, it is too early to say whether we should really think of this as widening access to education. The MOOC model may be understood as a very large scale process of information assimilation with standardised assessment. In some ways, these could be seen as the worst aspects of mechanical learning brought to a massive scale.

To avoid this kind of charge, most MOOCs rely on peer assessment of graded work and lively forum discussion to create communities and support structures that can replace classroom interaction and a personal relationship with an instructor.

There is a general tendency to think that the sheer scale of MOOCs will produce immersive learning communities. But perhaps this is overly optimistic. One blogger (Borden, 2012) reflecting on his experience of a statistics MOOC noted:

[A]fter asynchronous discussions with about 10 peers, I soon realized that I was likely the most knowledgeable person in our group when it came to statistics... nobody had anything of value to bring to the table. Social learning is indeed a powerful thing, but without what Vygotsky would call the "More Knowledgeable Other" in the group, it starts to break down quickly. MOOCs could rely solely on high stakes, standardized, auto-graded tests, but again, that would simply perpetuate a bad practice from face to face teaching in the online realm.

One of the most evident attractions of MOOCs is the ability to scale educational activities, but we need to be attentive to the kind of activities we scale. Organisers of MOOCs are under an obligation to demonstrate the validity of their instruction, but need to ensure that an over-reliance on learning analytics and machine learning does not restrict our idea of education to only those things which may easily be measured and quantified. Without basic cultural skills like reading there are few possibilities for Bildung (Ließmann, 2009) and if those taking part lack a certain basic standard of academic ability it is difficult to see what value they offer to others in peer-based assessment.

As McAuley, Stewart, Siemens, and Cormier (2010) found, student dropout in MOOCs is much higher than in traditional courses. Whether the majority of students feel that they get value from participating in a MOOC remains an open question. As we have seen from our overview of Bildung-theoretic perspectives, Bildung offers a way of making sense of (and informing) this kind of activity by providing an account of what 
meaningful interaction within a MOOC might look like: an activity which emphasizes curiosity, imagination, passion, and creativity in order to encourage authentic and personal forms of learning through open communities. There is a striking similarity between these digital learning activities and events that took place during educational journeys described in a literature of its own: bildungsroman (often translated as the coming-of-age novel).

Such narratives are etymologically and culturally rooted in the same idea as Bildung. In 1821, J ohan Wolfgang von Goethe published the novel Wilhelm Meister's J ourneyman Years which is considered to be the prototypical bildungsroman based on a trichotomy of (1) youth, (2) years of apprenticeship and wandering, and (3) master craftsmanship to describe the personal and biographical development of a fictional character. Beginning in the boyhood years, the author explains how Wilhelm Meister breaks out of his confining childhood home to find liberation in the world of theatre. Once he is out in the wild world, he is exposed to violence (robbery), a failed love affair, and other difficulties that he has to cope with throughout the journey of his life.

Learning in a MOOC has significant parallels to the wandering years of Wilhelm Meister. For instance, the experiences of the confining structures of the family may represent the closed learning management systems that have become predominant in higher education for a decade. As these systems get unbundled by implementing OER and OEP, learning is less predictable and more fragile (McAndrew, Farrow, Law, \& Cirigottis-Elliot, 2012) but also more conducive for Bildung because the vast amount of freedom requires the person to reflect more deeply, not only about learning per se but also about fundamental questions about life, that is, the notion that describes Bildung as a process of transformation, recognition of one's autonomy and potential, or going beyond the present state (Marotzki, 2003). Bildung is thus an existential process of becoming, not a fixed state or achievement.

In this regard, social media provides outstanding potential to elicit this process given their emphasis on networking, collecting and sharing, collaboration, articulation, and participation. More specifically, tools like Mendeley offer opportunities for identity management, creative handling of cultural objects, and reflexivity in public participation. The potential can be enhanced by a gradual opening to reach a larger community than traditional environments (classroom, online discussion forums). Using these tools can engage the learner in processes that are articulated in the tradition of the bildungsroman. 


\section{Conclusion}

The present paper has attempted to provide a theoretical base for an educational field that has gained enormous attention over the past years. Developments have been closely related to and thus mediated by innovative ICT. Consequently it has become challenging to keep track of the accomplishments of the open educational movement. Besides the consequences for practitioners (e.g., difficulties to find appropriate OER materials) there is also a significant downside with concern to scholarly work. As long as there is no solid theoretical foundation, the movement is in danger of becoming weakened, which was the case during the earlier open classroom movement in Germany that exploited openness as a buzzword during the struggle for more educational innovations and thus failed to be recognised as an influential field.

To bridge this gap, we have introduced the theory of Bildung which roots in philosophical and theological thinking (self-cultivation). We have briefly reviewed subsequent history to demonstrate how education has benefited from Bildung. With the recent advent of innovative ICT, media has become a core subject for Bildung. There is significant potential to elicit or encourage Bildung through the use of OER, such as through providing open access to a rich base of materials from various cultural contexts. In this process of engaging with multiple and complex resources it can be assumed that a transformation of the way in which the individual is approaching learning is likely to happen. We explored this through the context of MOOCs and argued that Bildung can provide a useful contribution to understanding and maximising the value of open education.

The beliefs and values associated with Bildung - including autonomy, critical reflection, inclusivity, and the rejection of commercial imperatives - are suitable for providing a theoretical framework for OER as well as providing a critical lens through which to assess contemporary educational models in practice (e.g., Lessman, 2006). The commercialization of higher education threatens to conflate education and learning, and learning experiences are often treated as isolated consumer choices. We need a framework like Bildung to analyse changes in education, helping us make decisions about the kind of educational culture to which we aspire. Overall, Bildung is more reflexive, more critical, and more open than didactic models of education or traditional theories of distance learning. There are good reasons to think that it can provide the open education movement with an improved philosophical and pedagogical foundation. 


\section{References}

Bell, F. (2011). Connectivism: Its place in theory-informed research and innovation in technology-enabled learning. International Review of Research in Open and Distance Learning, 12(3), 98- 108.

Borden, J . (2012). 'Flipping the MOOC?' Retrieved from http:// fwd.pearson.com/2012/09/27/flipping-the-mooc/.

Danaher, P. A., Wyer, D. W., \& Bartlett, V. L. (1998). Theorising open learning for researching home school and itinerant settings. Open Learning: The J ournal of Open, Distance and e-Learning, 13(1), 9- 17.

Daniel, S. J . (2012). Making sense of MOOCs: Musings in a maze of myth, paradox and possibility. Seoul: Korea National Open University.

Deimann, M. (2013). Open education and Bildung as kindred spirits. E-Learning and Digitial Media, 10(2), 190-199.

Downes, S., Siemens, G., \& Cormier, D. (2013). Change.Mooc.CA - How this course works. Retrieved from http:// change.mooc.ca/about.htm.

Dumont, L. (1994). German ideology: From France to Germany and back. Chicago: University of Chicago Press.

Engeström, Y. (2001). Expansive learning at work: Toward an activity-theoretical reconceptualisation. J ournal of Education and Work, 14(1), 133- 156.

Evans, T., \&Nation, D. (1992). Theorising open and distance education. Open Learning: The J ournal of Open, Distance and e-Learning, 7(2), 3- 13.

Fini, A. (2009). The technological dimension of a massive open online course: The case of the CCK08 course tools. International Review of Research in Open and Distance Learning, 10(5)

Geser, G. (2007). Open educational practices and resources: OLCOS Roadmap 2012. Salzburg: Salzburg Research.

Habermas, J . (1968). Erkenntnis und Interesse. Frankfurt am Main: Suhrkamp.

Horlacher, E. (2004). Bildung - A construction of a history of philosophy of education. Studies in Philosophy and Education, 23, 409-426.

Jörissen, B., \& Marotzki, W. (2008). Neue Bildungskulturen im „Web 2.0“: Artikulation, Partizipation, Syndikation. Internet - Bildung - Gemeinschaft (S. 203- 225). VS Verlag für Sozialwissenschaften. 
Kop, R. (2011). The challenges to connectivist learning on open online networks: Learning experiences during a massive open online course. International Review of Research in Open and Distance Learning, 12(3).

Lenzen, D. (1976). Offene Curricula - Leidensweg einer Fiktion. Lehrjahre in der Bildungsreform. Resignation oder Rekonstruktion? (S. 138- 162). Stuttgart: Klett.

Liessmann, K. (2006). Theorie der Unbildung: Die Irrtümer der Wissensgesellschaft. Wien: Zsolnay.

Marotzki, W. (2003). Bildung, subjectivity and new information technologies. Educational Philosophy and Theory, 35(2), 227- 239

Marotzki, W., \&J örissen, B. (2010). Dimensionen strukturaler Medienbildung. J ahrbuch Medienpädagogik, 8 (S. 19- 39- 39). VS Verlag für Sozialwissenschaften.

McAuley, A., Stewart, B., Siemens, G., \& Cormier, D. (2010). The MOOC model for digital practice. Retrieved from http:// www.elearnspace.org/Articles/MOOC_Final.pdfm

Meister, D. M., \& Meise, B. (2010). Emergenz neuer Lernkulturen Bildungsaneignungsperspektiven im Web 2.0. In B. Herzig, D. M. Meister, H. Moser, \& H. Niesyto (Hrsg.), J ahrbuch Medienpädagogik 8 (S. 183- 199). VS Verlag für Sozialwissenschaften.

Menck, P. (2000). Bilder- Bildung- Weltbild. Paedagogica Historica, 36(1), 93- 110.

Mendelssohn, M. (1997) [1784]. On the question: What does "to enlighten" mean? In D. O. Dahlstrom, (Ed. \& Trans.) Philosophical writings. Cambridge: Cambridge University Press..

Mezirow, J . (1997). Transformative learning: Theory to practice. New Directions for Adult and Continuing Education, 74(74), 5- 12.

Mozilla (2013). Learning/ Web literacies white paper. Retrieved from https:// wiki.mozilla.org/ Learning/WebLiteraciesWhitePaper.

Nehles, R. (1981). Offenheit - pädagogisches engagement ohne theorie? Frankfurt am Main: Lang.

Nyberg, D. (1975). The philosophy of open education. London: Routledge.

Peters, M. (2008a). The history and emergent paradigm of open education. Open education and education for openness (S. 3- 15). Sense Publishers. 
Peters, M. (2008b). Open education and education for openness. Rotterdam: Sense Publishers.

Smith, M. S., \& Casserly, C. M. (2006). The promise of open educational resources. Change: The Magazine of Higher Learning, Sep-Oct 2006, 38(5), 8.

Sorkin, D. (1983). Wilhelm Von Humboldt: The theory and practice of self-formation (Bildung), 1791-1810. J ournal of the History of Ideas, 44(1), 55-73.

Vandenberg, D. (1975). Openness: The pedagogic atmosphere. The philosophy of open education (S. 35- 57). Routledge \& Kegan Paul.

Weller, M. (2011). A pedagogy of abundance. Spanish J ournal of Pedagogy, 249, 223236.

Wellmon, C. (2010). Becoming human: Romantic anthropology and the embodiment of freedom. University Park: Pennsylvania State University Press.

Wiley, D. (1998). Open content license. Retrieved from http:// opencontent.org/opl.sthml

\section{Web sites}

MIT OCW http://mitx.mit.edu/

OLnet http:// ci.olnet.org

OERGlu http:// www.oerglue.com

OER Knowledge Cloud https:// oerknowledgecloud.org/

OpenLearn http:// www.open.edu/ openlearn

OpenStudy http:// openstudy.com

P2PU http:// p2pu.org/ en/

Wikieducator http:// wikieducator.org/_Main_Page

\section{Athabasca University $\mathbf{a}$}

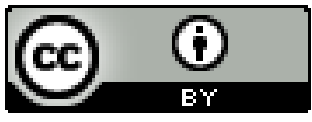

